\title{
INTERDISCIPLINARIDADE E ERRO CATEGORIAL NA VIA DA INTERCONEXÃO DO CAMPO DOS DIREITOS HUMANOS E AS CIÊNCIAS
}

\author{
Aline Santos LEITE ${ }^{1}$ \\ Ricardo Barbosa de LIMA ${ }^{2}$
}

RESUMO:

O presente artigo tem por objetivo demonstrar que este novo método do conhecimento, a interdisciplinaridade, somente torna-se viável, na medida em que se considerem consistentes os próprios limites disciplinares, e que não ocorra erro categorial dentro do contexto das significações. Para tanto, buscaremos através da história da ciência e das concepções filosóficas, a importância da aplicação do Princípio da Não Contradição (PNC) em Aristóteles - a interdisciplinaridade deve ser capaz de operar o PNC, que é a condição de possibilidade do sentido, evitando o equívoco - e a distinção entre conhecer e pensar, na Crítica da Razão Pura em Kant - os conflitos teorizados no campo das humanidades e mais especificamente no campo de conhecimento dos direitos humanos, que possuem objetos que necessariamente são pensados e conhecidos, podem se relacionar, através de uma análise epistemológica tendo como ponto de partida: a razão, e, ponte de conexão: a relação. A interdisciplinaridade se daria na capacidade de distinguir fenômeno e noumenon, e, discernir a relação entre conceitos, sejam eles conhecidos ou pensados.

\section{PALAVRAS-CHAVE:}

Interdisciplinaridade; Conhecimento; Ciências Humanas.

\section{INTRODUÇÃO}

O debate entre abordagens disciplinares e posdisciplinares (inter, multi e transdisciplinares), antes de desfazer o abismo entre as duas grandes culturas que definem os campos das ciências duras e das humanidades, podem reconstruí-lo e fortifica-lo à medida que reestabelece a dicotomia entre "nós" e "eles". A problemática apresenta-se quando a estrutura necessária à pertinência de diálogo entre estes dois campos torna-se, ou confusa - provocando um embaralhamento de ideias que produz percas inestimáveis para ciência - ou quando 
reforça ainda mais os pontos de divergência, afastando-se definitivamente da confluência pretendida.

Apesar da estruturação do saber receber fortes influências por uma estruturação pósdisciplinar, esta mudança acelerada ao invés de produzir um diálogo natural entre as áreas vem muitas vezes acentuando as diferenças e causando o estranhamento da razão. Este trabalho advoga que antes disso, de engrossar esta ou aquela trincheira, é necessário dar um passo atrás e buscar marcos racionais que permitem fornecer critérios mínimos de reconhecimento do que dá forma e legitimidade ao conhecimento científico e seus princípios fundadores. Busca experimentar a possibilidade de interconexão destes campos extremos através de uma suposta interdisciplinaridade, compreendida dentro da perspectiva da relação entre as relações construídas nas especificidades disciplinares, e a consideração das mesmas pela razão.

Tem por objetivo demonstrar que este novo método do conhecimento, a interdisciplinaridade, somente torna-se viável, na medida em que se considerem consistentes os próprios limites disciplinares, e que não ocorra erro categorial dentro do contexto das significações. Para tanto, buscaremos através da história da ciência e das concepções filosóficas, a importância da aplicação do Princípio da Não Contradição (PNC) em Aristóteles - a interdisciplinaridade deve ser capaz de operar o PNC, que é a condição de possibilidade do sentido, evitando o equívoco - e a distinção entre conhecer e pensar, na Crítica da Razão Pura em Kant - os conflitos teorizados no campo das humanidades e mais especificamente no campo de conhecimento dos direitos humanos, que possuem objetos que necessariamente são pensados e conhecidos, podem se relacionar, através de uma análise epistemológica tendo como ponto de partida: a razão, e, ponte de conexão: a relação. A interdisciplinaridade se daria na capacidade de distinguir fenômeno e noumenon, e, discernir a relação entre conceitos, sejam eles conhecidos ou pensados.

\section{LIBERDADE POR DIGNIDADE E AS CIÊNCIAS}

A clareza quanto à abrangência dos campos de estudos envolvidos é requisito primordial para a construção de um entendimento racional quando da interconexão de extremos. Dentro do universo das humanidades, a amostra se dará no campo de estudos dos direitos humanos, mais especificamente com a definição de liberdade como princípio basilar da dignidade humana. 


\section{INTERDISCIPLINARIDADE E ERRO CATEGORIAL [...]}

Ocupar-se da promoção dos direitos humanos é trabalhar as condições necessárias para fazer com que, a dignidade humana seja entendida como ponto de partida inarredável e princípio norteador, na promoção de ações e políticas públicas que visam à satisfação das condições, não mínimas, mas suficientes ao bem estar humano. Dignidade, a partir da perspectiva do campo de estudos dos direitos humanos, por seu conteúdo complexo e seu aspecto abstrato, é um conceito difícil de ser determinado. São frequentes as críticas e os arranjos à progressiva afirmação da dignidade humana, o que nos leva cogitar que esta ideia talvez "só possa ser concebida como axioma, como valor máximo atribuído a um ente, como aquele objeto irreal inestimável que reside num ente real (homem)" (MARQUES, 2010: 565).

A dignidade é um valor incondicionado, um caráter único e insubstituível, no qual, a palavra respeito constitui a expressão do que o ser deve-se prestar. Para Kant a dignidade define-se na afirmação de que "o homem - e, de uma maneira geral, todo o ser racional existe como fim em si mesmo, e não apenas como meio para o uso arbitrário desta ou daquela vontade" (KANT, 2003, p. 58).

Ao considerarmos a dignidade humana como cerne dos direitos humanos, faz-se necessário um esforço por concretizá-la à luz dos influxos históricos e culturais de cada sociedade. Sua concepção deve fundar-se temporalmente na dignidade igual de cada ser humano - sujeito moral, sujeito jurídico, sujeito político e sujeito social - e na dignidade da liberdade, em sua concepção mais ampla, que permita ao homem exercer plenamente os seus direitos existenciais. A ideia de dignidade que adotamos nesta comunicação identifica-se com o significante, liberdade.

A liberdade, como autodeterminação, é uma importante característica na afirmação da dignidade humana e se expressa por um empoderamento que permite ao ser humano, de forma livre, traçar seu destino. Liberdade é o fundamento que possibilita a aquisição da emancipação individual e da consciência coletiva necessária para a superação a qualquer tipo de dominação. Esta emancipação dá a quem desejar decidir e controlar seu próprio destino com responsabilidade e respeito ao outro. Afirma Mirandola:

O homem pode modificar a si mesmo. Liberdade é um poder de ação. Caberá, depois, ao desenvolvimento da filosofia, em reflexão conjunta com a ciência, aduzir outros elementos para completar essa noção de liberdade. Mas o fundamento está posto de maneira sólida. (MIRANDOLA, 1988, P. 22).

Dentro das inúmeras acepções ao longo da história da filosofia e da ciência, Kant fundamenta a dignidade humana na liberdade, certo de que no tempo em que as liberdades de 
cada um sejam viabilizadas de forma harmônica dentro do contexto social, a dignidade humana eclodirá. Para este autor, liberdade é a ideia que tem o dever de ser correlata a todo ser humano. A todo ser racional que possui vontade atribui-se a ideia de liberdade, sob a qual somente ele poderá agir.

\begin{abstract}
"Ninguém pode me constranger a ser feliz a sua maneira (como ele concebe o bem estar dos outros homens) a cada um é permitido buscar a sua felicidade pela via que lhe parecer boa, contanto que não cause dano à liberdade dos outros (isto é, ao direito de outrem) aspirarem a semelhante, que pode coexistir com a liberdade de cada um, segundo uma lei universal possível" (KANT, 1998)
\end{abstract}

A liberdade para Kant constitui o fundamento que torna possível toda ação livre quanto ao tempo e torna possível a autonomia da razão frente à natureza. A perspectiva da liberdade é constituída como, "a faculdade de iniciar por si mesma um estado, cuja causalidade não tem causa, pois não está por sua vez, segundo a lei da natureza, sob outra causa que a determinou quanto ao tempo" (KANT, 1787: b474).

Torna-se, neste ponto, pertinente esclarecer que, apesar da liberdade ser definida por uma causalidade sem causa, para Kant a liberdade não é livre arbítrio. Ela é a condição que o homem possui para agir corretamente guiando-se pela razão. Liberdade, portanto, é uma lei incondicional que o sujeito da ação recebe de si mesmo independente das circunstâncias e das necessidades naturais e instintivas do homem. A liberdade está na razão e é por ela que o homem recebe a referência correta à sua atitude.

Ao nos dirigirmos ao outro campo, o qual, com a liberdade, queremos relacionar, isto é, o campo da ciência, procuramos, assim como Kant, defini-lo como a noção do conhecimento empírico do mundo, que implica na noção de necessidade, que é a condição do que não pode não ser, isto é, tem que ser.

Falar de ciência é falar de conjuntos de conhecimentos que se exprimem em enunciados e conceitos. Um conhecimento científico é expresso num juízo, constitui uma síntese ou unidade. Kant dá a estes conhecimentos o nome de juízos sintéticos a priori. Para melhor entender o que é um juízo científico, o autor distingue-o dos juízos analítico e sintético a posteriori.

Todos os juízos consistem em uma relação entre um sujeito e um predicado, podendo este ser, afirmado ou negado do sujeito. No juízo analítico o predicado está contido no sujeito e, portanto, basta analisar o sujeito para explicitar ou revelar o predicado. É um juízo 


\section{INTERDISCIPLINARIDADE E ERRO CATEGORIAL [...]}

explicativo e universal uma vez que está contido no sujeito com validade temporal e em todos os lugares.

No juízo sintético a posteriori o predicado é algo que se acrescenta ao sujeito, não se deduz deste porque não está contido no seu conceito. A atribuição do predicado ao sujeito tem o seu fundamento na experiência. O juízo sintético a posteriori, embora aumente o nosso conhecimento, pois nele o predicado acrescenta algo ao sujeito, não é um juízo propriamente científico.

Os juízos científicos se diferenciam dos juízos sintéticos a posteriori, pois estes são contingentes, válidos somente para o momento, ou o tempo da observação, e para o observador. A ciência consiste em juízos cuja universalidade ou necessidade não admite exceções. Juízo científico é o resultado do encadeamento lógico das ideias que auxiliam o homem na descoberta progressiva das estruturas dos sistemas existentes na natureza e de suas formas de funcionamento. Constitui-se de ações que passam por fases de experimentação, de análise e de síntese para chegar a noções racionais, definitivas ou provisórias.

São visíveis as divergências contidas nos campos acima descritos e a via da interconexão dos mesmos geram conflitos e apontam um problema típico de interdisciplinaridade.

\section{DIREITOS HUMANOS E INTERDISCIPLINARIDADE: LIBERDADE X CIÊNCIA}

O processo de conhecimento vem recebendo fortes influências por uma estruturação pós-disciplinar, mas esta mudança acelerada ao invés de produzir um diálogo natural entre as áreas vem acentuando as divergências e causando o estranhamento da razão. A própria definição da interdisciplinaridade é, pelo menos por hora, uma complicada tarefa. A dificuldade inicial não está somente no fato de haverem díspares definições a partir daqueles que tomaram este termo como objeto de estudo, mas também na constatação de que, aqueles que a teorizam, muitas vezes não sabem como colocá-las em prática, e os que dizem praticar, não conseguem defini-la.

De forma generalizada e destacando os pontos de congruência dentro dos vários conceitos já teorizados, utilizamos como ponto de referencia a ideia de que interdisciplinaridade é o termo que vem sendo utilizado para nomear o que pretendemos entender como a desconstrução dos muros disciplinares em prol do cruzamento de especialidades. Seria uma espécie de novo campo do conhecimento, estruturado na 
interconexão necessária das especialidades, cujo propósito, na maioria das vezes, vem sendo utilizado na solução de problemas complexos que à ciência fragmentada faltam mecanismos de superação.

A verdade é que não há ainda uma estabilidade nestas idéias. Muitos dos trabalhos hoje classificados como interdisciplinares, nada mais são, que uma tentativa de se agrupar conhecimentos de diversas especialidades em um mesmo contexto, ou, passá-los por um processo de fusão onde o resultado final parece-nos menos rico do que os elementos iniciais, uma vez que se perdem pontos importantes da pesquisa. A interdisciplinaridade, nesta fórmula, nada mais contribui do que ser apenas uma prática que se expressa através de uma justificação estritamente técnica.

Esta é a problematização que se faz aqui da interdisciplinaridade principalmente quando relacionamos "as duas culturas" de C.P. Snow (1959): as ciências físicas, matemáticas e experimentais que se posiciona num extremo da estrutura disciplinar e do outro as ciências humanas. A dificuldade não se restringe somente à definição do termo, mas também em como colocá-la em prática, e, neste caso, em como estender esta premissa ao campo dos direitos humano, sem o prejuízo de conhecimentos que envolvam problemas de pesquisas pedintes de análise complexa e interpretação conceitual.

É fato que, à própria construção do campo de estudos dos direitos humanos, postulouse como necessidade primaria, a articulação de especialidades que partiam de diferentes áreas do conhecimento. A necessidade de se dar conta dos problemas inerente à luta dos direitos humanos - problemas de diferentes naturezas e com níveis de complexidade crescentes - pede por diálogos, não só entre especialidades de áreas de diferentes, mas também entre saberes disciplinares e não disciplinares dependendo do nível de complexidade do fenômeno a ser tratado.

Mas, se os estudos dos direitos humanos, expresso no termo "liberdade" e a "ciência" são ramos tão distintos, sua interconexão torna-se necessariamente um problema interdisciplinar. Como então tornar possível a prática interdisciplinar e como podemos pretender realizá-la sem cairmos nos vícios de justaposição ou fusão de ideias?

Por justaposição, entendemos um todo cujas partes se mantêm meramente justapostas sem articulação internas entre si. Já a fusão é um todo no qual a deficiência entre as partes foi perdida em benefício do todo. A interdisciplinaridade deve ser praticada não por justaposição ou fusão e sim como uma unidade sistêmica, que se define como um todo, cuja unidade se dá, 


\section{INTERDISCIPLINARIDADE E ERRO CATEGORIAL [...]}

não apesar, mas através das diferenças entre as partes, de tal modo que cada parte só é o que ela é, porque todas as outras, que não são ela, são o que elas são.

O que equivale dizer que, diante das variáveis culturais, temporais, conceituais e linguísticas aclamadas dentro das diversas áreas convocadas ao complexo estudo dos direitos humanos, surge a necessidade de se articular dúvidas sistêmicas, o que significa refazer, segundo Bourdieu (1983) a vigilância epistemológica e reabrir o espaço da pesquisa à incerteza com princípios, inclusive entre as ciências, para um novo paradigma científico.

Diante deste labiríntico cenário que a via de interconexão dos direitos humanos e as ciências nos apresenta, pretendemos adiantar, por hipótese, duas situações onde há a possibilidade de se articular interdisciplinaridade: a realização da mesma dentro da perspectiva das relações, e, a consideração da mesma pela razão, levando em consideração a forma e não o objeto, e em ambas respeitando-se os limites da disciplinaridade e evitando a ocorrência de erro categorial.

Os limites da disciplinaridade e o erro categorial

A imprescindibilidade para que a interdisciplinaridade seja construída respeitando os limites da disciplinaridade, é apresentada em sua própria etimologia. Disciplina provém do latim disciplina, que significa "o que se aprende". Este termo é hoje conhecido como "ramo do conhecimento específico", como componente de um currículo. Já o prefixo "inter” denota "dentro de", “entre". A interdisciplinaridade pressupõe uma convergência, uma complementaridade, o que significa, ao mesmo tempo, uma transferência de conceitos teórico-metodológicos e a combinação de diferentes áreas do conhecimento.

Promover um diálogo interdisciplinar para tratamento do campo de direitos humanos é considerar as especificidades e regras no interior de cada campo científico, conforme aponta Soares (1991: 264), um primeiro passo para tratar dos problemas e desafios da interdisciplinaridade, no sentido de construir o "rigor da indisciplina", é justamente dar um passo atrás e reconhecer que, independentemente das diferentes vias de tratar a questão, "cuja matriz é a divisão entre disciplinas, evidentemente a diferenciação disciplinar, sua pertinência e funcionalidade estão pressupostas".

Kant nos diz: "não há acréscimo, mas desfiguração da ciência quando se confunde seus limites" (1787: BVIII). Uma análise superficial de suas obras parece-nos dizer que o autor não era defensor do que agora denominamos posdisciplinaridades. Mas, ao contrário do 
que aparenta, este autor considerava que a preposição da disciplinaridade era necessária para que tenhamos uma posição rigorosa da interdisciplinaridade.

Mas como proceder à interdisciplinaridade, sem desconsiderar os limites deste fenômeno fundamental da história da ciência - o processo de fragmentação das disciplinas formais - se, parece-nos quimérico pretender dominar duas ou mais especialidades na sua totalidade?

Segundo Dogan (1996: 91-92), pesquisar utilizando-se de muitas disciplinas envolve uma combinação de segmentos de disciplinas, especialidades, e não de disciplinas inteiras. A especialização "no limite da ciência é raramente monodisciplinar", desta forma o "ponto de contato frutífero é estabelecido entre especialidades, entre setores, e não ao longo de toda a fronteira entre disciplinas".

Inter-relacionar disciplinas inteiras é desconsiderar a importância das mesmas como especialidades e descaracterizar o processo de interdisciplinaridade, que se constitui na relação entre elas.

A interdisciplinaridade pressupõe uma convergência, uma complementaridade, o que significa, de um lado, a transferência de conceitos teóricos e de metodologias e, de outro, a combinação de áreas. Assim, por exemplo, "a sociologia pode utilizar conceitos da economia, como faz Pierre Bourdieu quando se serve dos conceitos de capital, mercado e bens para todas as atividades sociais e não somente as econômicas, ou quando faz largo uso da noção de troca" (FIORIN, 2008). Com constância, a interdisciplinaridade dá origem a novos campos do saber através da transferência de conceitos, metodologias e técnicas desenvolvidas de uma ciência para outra e por uma intersecção de disciplinas, que se reorganizam, que buscam elementos noutras ciências, mas, que ao mesmo tempo não apagam seus próprios contornos.

Outro ponto importante a ser tratado, na idealização da interdisciplinaridade, é a capacidade de identificar "erro categorial". Erro categorial é o equívoco, acerca do verbo "ser", tomado o verbo como operador copulativo da preposição (ligação entre o sujeito e o predicado). Comete-se erro categorial quando não se faz a distinção categorial, isto é, erro cometido pela não variação da categoria dos sentidos.

O erro categorial é demonstrado no "Princípio da Não Contradição" - PNC, no livro Gama da Metafísica de Aristóteles, "o mesmo ser e não ser ao mesmo tempo e no mesmo sentido é impossível". Uma coisa é aquilo que ela é, e não pode ser outra coisa, simultaneamente. Se algo é o que é, e ao mesmo não o é, uma só coisa seria tudo. Não é 


\section{INTERDISCIPLINARIDADE E ERRO CATEGORIAL [...]}

possível que predicados contrários possam coexistir no mesmo sujeito, não ao mesmo tempo e no mesmo sentido.

A interdisciplinaridade deve ser capaz de operar o PNC, que é a condição de possibilidade do sentido, da significação, de polissemia. Polissemia é a identificação da multiplicidade de sentidos sem a contradição, equivoco é o engano produzido pelo mesmo significante (equivocidade $=$ mesmo som). Para a construção de uma teoria/prática interdisciplinar do campo dos direitos humanos e as ciências é necessário que a interdisciplinaridade suponha discernimento da polissemia e evite o equivoco. A trilha da Interdisciplinaridade é aquele que se estende entre o "fio da navalha" entre a polissemia e o equívoco. A virtude da interdisciplinaridade é a sapiência de identificar que uma mesma palavra tem a propriedade de se apresentar em mais de um significado nos múltiplos contextos em que aparece. A contradição surge na maioria das vezes, quando supostamente houve um erro categorial na análise dos campos a serem inter-relacionados.

O PNC, quando negado, isto é, o mesmo pode ser e não ser ao mesmo tempo e no mesmo sentido, desestrutura o processo de significação. Todo raciocínio deve ter como principio, o da "não contradição", pois, este princípio não é uma mera hipótese, mas sim, “algo seguro, sobre o qual é impossível errar" (Aristóteles, Perini, 2002: 143).

Interdisciplinaridade deve ser hábil a trabalhar com diversos sentidos ao mesmo tempo. Não é dizer que algo é certo e errado ao mesmo tempo, é dizer que algo pode ser certo na categoria de sentido $\mathrm{x}$, e também ser certo na categoria de sentido y. Uma mesma coisa pode ser ao mesmo tempo muitos objetos desde que sobe diferentes abordagens. A partir do momento em que relacionamos argumentos de diferentes áreas científicas (ou não) para tratarmos dos temas inerentes aos direitos humanos, certamente se os tomarmos no mesmo sentido, e ao mesmo tempo, inúmeras contradições irão surgir.

O debate da dignidade humana, liberdade ou igualdade, por exemplo, está no campo da semântica, a definição dos seus conceitos é a discussão. Suas definições quando vistas em diferentes áreas apresentam-se em formas divergentes, mas não devem ser polemizadas, se forem apenas consideradas contrárias em diferentes sentidos. Daí surge a ideia da relação, interdisciplinaridade não consiste em mesclar conteúdos com o fim de originar uma nova disciplina, não é a resposta esperada para por fim aos problemas conteudistas, a interdisciplinaridade trabalha no sentido das relações entre teorias e metodologias originadas em diferentes contextos. 


\section{DISTINÇÃO ENTRE CONHECER E PENSAR EM KANT}

Considerando as hipóteses levantadas, a interdisciplinaridade deve ser experimentada dentro da perspectiva das relações e pela forma e não pelo conteúdo. A questão que surge neste contexto é como estabelecer relações interdisciplinares entre as especialidades das ciências "duras" e "filosóficas" e/ou não científicas?

Para iniciarmos este entendimento, buscaremos em Kant a diferença entre "conhecer" e "pensar" que se apresenta na sua obra intitulada "Crítica da Razão Pura" (1787).

Para Kant, todo objeto, para ser conhecido, deve sujeitar-se à sensibilidade, ao espaço e ao tempo, e, às formas do entendimento. Por sensibilidade entendemos como dados recebidos pela intuição, isto é apreensão sensorial. O entendimento é a faculdade de buscar regras em geral dos dados sensíveis. O processo que unifica a sensibilidade e o entendimento tem como resultado, o conhecimento universalmente válido. Desta forma, quando uma investigação científica toma por objeto, por exemplo, a matemática e a física, podemos dizer que esta é possível, porque seus objetos estão de acordo com a proposta kantiana dos juízos sintéticos a priori.

Mas, a rigor, o entendimento não é a única faculdade que opera segundo conceitos, pois esta também é a verdade da razão. A distinção kantiana entre entendimento e razão parece ser uma distinção entre dois modos de operar com conceitos: na primeira, aplicando-os aos objetos da experiência - conhecer - e na segunda, formando novos conceitos, aos quais nenhum objeto de qualquer experiência possível corresponde - pensar.

Não é tudo que pode ser conhecido pelo entendimento humano. Segundo Kant há determinados objetos - como o objeto de nosso estudo a liberdade - que se encontram para além de uma experiência possível. Estes são os objetos da metafísica e toda tentativa de se aplicar juízos sintéticos a priori termina em infinitas contradições. Dentro deste impasse, Kant nos traz a diferenciação entre fenômeno e nôumeno, e coloca o homem como o centro da investigação.

Segundo Kant, fenômeno é tudo aquilo que aparece aos sentidos do sujeito quando este estabelece uma relação com o objeto. O fenômeno é aquilo que pode ser conhecido da realidade. Já o nôumeno é a coisa em si mesma, uma característica da realidade que não pode ser apreendida pelo entendimento. Abbagnano diz: "este termo foi introduzido por Kant para indicar o objeto do conhecimento intelectual puro, que é a coisa em si” (1999, p.718). O nôumeno não pode ser conhecido porque não se sujeita à relação de causa e efeito existente na R. Fac. Dir. UFG, v. 38, n.2, p. 269 - 282, jan. / jun. 2014 


\section{INTERDISCIPLINARIDADE E ERRO CATEGORIAL [...]}

natureza. Kant esclarece que o resultado da união entre entendimento e sensibilidade só pode alcançar o fenômeno. Entre o fenômeno e o nôumeno, de uma mesma realidade, só se conhece o fenômeno. As ideias metafísicas, dentre elas a liberdade, não possuem conteúdos que possibilitem a verificação da sua existência na realidade concreta.

Esta divisão do objeto em uma parte cognoscível e outra incognoscível nos possibilita compreender que, para Kant, “o entendimento humano é limitado para emitir juízos válidos sobre a realidade na sua totalidade, e, as ideias de Alma, Mundo, Deus e Liberdade são impossíveis de serem aceitas no campo do conhecimento científico" (Silva, 2003: 103). Quando buscamos conhecer o objeto da ação - a liberdade - a razão entra em conflito consigo mesma e consequentemente, o nosso conhecimento acerca do conceito liberdade torna-se problemático.

Mas se não podemos conhecer a liberdade como relacioná-la com as ciências? Como estabelecer uma correspondência entre a noção de contingência e de espontaneidade com a noção de verdade e necessidade? É neste ponto que a distinção entre conhecer e pensar de Kant dá subsídios para que se faça esta correlação. Os objetos em si - nôumeno - não podem ser conhecidos, mas podem ser pensados. Para Kant, pensar um objeto não implica necessariamente que ele tenha uma existência real.

O pensar para Kant envolve a projeção categorial (os conceitos). O pensar nos dá categorias que são conceitos independentes da matéria. Por isso é que podemos pensar mais coisas do que conhecer, pois não nos é possível ter acerca de liberdade, por exemplo, uma intuição sensível. Não podemos conhecer a liberdade, tendo em vista que não podemos acessá-la através de nossa sensibilidade, mas podemos pensar a liberdade.

Conflitos teorizados dentro do campo do conhecimento dos direitos humanos que possuem objetos que necessariamente, e por exclusão, podem ser pensados e conhecidos, podem ser relacionados se partimos para a análise epistemológica tendo como ponto de partida a razão (forma conceitos os quais nenhum objeto de qualquer experiência possível corresponde), e o ponto de conexão, a relação. Daí a essência deste campo de conhecimento ser interdisciplinar. Somente a razão, determinando por si mesma a vontade, é uma verdadeira faculdade superior do pensar. Um ser racional não pode conceber seus princípios subjetivos práticos, suas máximas, como leis universais.

Proposições feitas dentro do campo de estudos dos direitos humanos muitas vezes, contrárias entre si, e igualmente provadas segundo a lei da própria razão, por exemplo, a questão do universalismo e do multiculturalismo, a implicação dos direitos dentro de uma 
liberdade individual ou de uma liberdade coletiva, podem estabelecer conexões se aprendermos a executar uma interdisciplinaridade baseada nas relações das relações.

A interdisciplinaridade, dentro desta nova perspectiva, se daria na capacidade de distinguir as categorias (fenômeno/noumeno) e saber discernir que, o que se relaciona dentro de um conceito pode ser encontrado nas relações compreendidas em outros conceitos, sejam estes conhecidos ou pensados, sem, contudo, incidir em erro categorial e respeitando os limites das disciplinas.

A relação dos conteúdos na interdisciplinaridade estaria no "assim como", por exemplo: o conceito de liberdade está para Filosofia assim como a democracia está para a Sociologia, assim como o sujeito de direito está para o Direito, assim como a dignidade humana esta para os Direitos Humanos. A riqueza da interdisciplinaridade é a sapiência de se constituir novos conhecimentos a partir de relações entre conceitos já constituídos dentro das disciplinas, sem comprometer seu significado, evitando assim o erro categorial e produzindo elementos capazes de contribuir não só para a compreensão e possível busca para soluções de problemas de alta complexidade, mas também para uma nova estruturação dos saberes.

\section{CONSIDERAÇÕES FINAIS}

A contribuição positiva da Crítica da Razão Pura de Kant é vista pelo próprio como uma carta de permissão para que o campo das humanidades se estenda "para além dos limites da sensibilidade", sem que, com isso, a razão entre em contradição consigo mesma (KANT, 1787, AB XXV). Enquanto o conhecimento requereria sempre a aplicabilidade dos conceitos a um domínio sensível de interpretação, o pensamento poderia se libertar de tal exigência. Assim, todos os conceitos que a princípio seriam do objeto do conhecimento poderiam ser pensados, mas nem todo objeto do pensamento poderia ser conhecido.

O mundo o qual nós podemos ter acesso e no qual para além de conhecer nos é facultado pensar é um mundo onde tem o lugar próprio, a dignidade do homem. A liberdade não pode ser objeto da experiência, pelo menos não de uma ciência como a ciência física, e é isto que o $3^{\circ}$ conflito das ideias transcendentais mostra. Da mesma forma, não há como procurar um sentido único de dignidade humana, o qual poderia ser resultado de uma experiência científica, tendo em vista que, a mesma não pode ser conhecida, apenas pensada.

A via de conexão entre os direitos humanos e as ciência, dentro do mundo do conhecer e do pensar, só será satisfeita se envolver a capacidade de relacionar os diversos sentidos de R. Fac. Dir. UFG, v. 38, n.2, p. 269 - 282, jan. / jun. 2014 


\section{INTERDISCIPLINARIDADE E ERRO CATEGORIAL [...]}

um mesmo conceito, sem ocorrer em erro categorial e sem a descaracterização dos limites das especialidades.

\section{REFERÊNCIAS BIBLIOGRÁFICAS}

ABBAGNANO, Nicolas. Dicionário de Filosofia. São Paulo: Martins Fontes, 1999.

ARISTÓTELES. Metafísica, livro IV. Tradução de Marcelo Perine. São Paulo: Edições Loyola, 2002. V. 2.

ANGIONI, Lucas. Introdução à Teoria da Predicação em Aristóteles. Campinas, SP. Editora da Unicamp, 2006.

BOURDIEU, Pierre. Coleção Grandes Cientistas. São Paulo: Ática, 1983.

DOGAN, Mattei. Fragmentação das Ciências sociais e recombinação de especialidades em torno da Sociologia. In: Revista Sociedade e Estado, volume XI, nº 1, Jan/Jun. 1996.

FIORIN, José Luiz. Linguagem e interdisciplinaridade, Alea: estudos latinos, vol.10 no.1 Rio de Janeiro Jan./June 2008, http://dx.doi.org/10.1590/S1517-106X2008000100003

KANT, Immanuel. Fundamentação da Metafísica dos Costumes. São Paulo: Martin Claret. 2003.

Sobre a expressão corrente: isto pode ser correto na teoria, mas nada vale na prática. A paz perpétua e outros opúsculos. Lisboa: Edições 70, 1988.

Crítica da Razão Pura. Segunda edição, 1787. Tradução de Manuela Pnto dos Santos e Alexandre Fradique Morujão.

MARQUES, Mário Reis. A dignidade humana como prius axiomático. Coimbra, Coimbra Editora, 2010, Vol. IV.

PICO DELLA MIRANDOLA, Giovanni. A dignidade do homem. São Paulo: GRD, 1988.

SILVA, Ailton, José da. A Noção de Liberdade na Terceira Antinomia da 'Crítica...' 103.

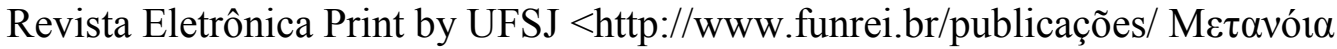

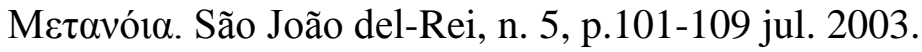

SOARES, L. E. Faça a coisa certa: o rigor da indisciplina. In: BOMENY, H. E BIRMAN, P. (orgs.) As assim chamadas ciências sociais: formação do cientista social no Brasil. Rio de Janeiro: UERJ, 1991. PP. 265-278. 
${ }^{1}$ Mestre em Direitos Humanos pela Universidade Federal de Goiás.

${ }^{2}$ Professor do Curso de Sociologia da Universidade Estadual de Goiás. E-mail: ricardo.ufg@gmail.com

Artigo recebido em 15 de março de 2014 e aceito em 30 de junho de 2014 